\title{
Public Health Campaigns and Medicine Use Awareness: A Systematic Literature Review
}

\author{
Mahsa Ranjbar ${ }^{1}, Z^{2 o e}$ Aslanpour ${ }^{1}$, Andrzej Kostrzewski1 ${ }^{1}$, Andrew David Cooke ${ }^{2}$ \\ ${ }^{1}$ School of Life and Medical Sciences, University of Hertfordshire, Hatfield, United Kingdom \\ ${ }^{2}$ Clinical Commissioning Group Bedfordshire, Bedford, United Kingdom \\ Email:m.ranjbar@herts.ac.uk, z.aslanpour@herts.ac.uk, andrzej.kostrzewski@btinternet.com, \\ Andrew.cooke@bedfordshireccg.nhs.uk
}

How to cite this paper: Ranjbar, M., Aslanpour, Z., Kostrzewski, A. and Cooke, A.D. (2017) Public Health Campaigns and Medicine Use Awareness: A Systematic Literature Review. Health, 9, 1689-1710. https://doi.org/10.4236/health.2017.912124

Received: October 19, 2017

Accepted: November 27, 2017

Published: November 30, 2017

Copyright (c) 2017 by authors and Scientific Research Publishing Inc. This work is licensed under the Creative Commons Attribution International License (CC BY 4.0).

http://creativecommons.org/licenses/by/4.0/

\section{(c) (i) Open Access}

\begin{abstract}
This study investigates the medicine awareness, which can be defined as the increase in knowledge and understanding of the general public on appropriate medicine use. Objective: To identify the characteristics of Public Health campaigns that focus on medicine use and/or medicine awareness. Study Design: Systematic review focusing on pre- and post-campaign surveys. Methods: Electronic databases: PubMed, Science Direct, Web of Knowledge, Scopus, Global Health, and Google Scholar were searched. Articles within the last 10 years, with a focus on adults over the age of 18 were used to report findings. Results: A total of 4336 studies were reviewed after which eight were identified, which focused on medicines use and/or awareness. Most campaigns emphasized the knowledge and understanding of patients on the importance of appropriate medicine use and drew a comparison from pre- to post-campaign results. A limited number of Public Health campaigns demonstrated an increase in the level of medicines use awareness of patients. Various tools were used to portray the message across in the campaigns. These included, video, written information, face to face approaches, as well as educational games. Four studies demonstrated a statistically significant increase, in awareness of the public in regards to medication. However, the remaining studies were not successful in portraying a significant impact. Conclusion: Most campaigns demonstrated a limited increase in level of medicine use awareness in their post-campaign surveys. The results support the need for a comprehensive Public Health campaign that focuses on medicine use.
\end{abstract}

\section{Keywords}

Medication Use, Medicine Use, Awareness, Campaign, Public Health 


\section{Introduction}

In the past decade, a growing number of researchers and healthcare professionals have become increasingly aware that patients fail to take their medications and follow prescribed treatment regimes, causing substantial loss in terms of both life quality and financial resource [1]. Within primary care in the UK, approximately $£ 300$ million worth of medicines are wasted every year of which $£ 150$ million is avoidable [1]. Approximately $50 \%$ of individuals in developed countries fail to take their medications as prescribed [2]. Public Health campaigns can be used to alter such behaviours and raise awareness on the importance of appropriate medicine use.

Public Health is a multi-disciplinary field that prevents disease, promotes a better quality of life, and creates environmental conditions in which people can be healthy by intervening at the institutional, community, and societal level [1]. Public Health campaigns are used across the world for different purposes and they are mainly based on psychological theories. Such theories aim to understand the influence of various factors on decision-making behaviour of individuals on health issues and their consequent solutions [3]. The effectiveness of a campaign is measured through a pre- and post-comparison study [4].

The contribution of behavioral factors has been reviewed by investigating the impact of educational programs in regards to medication use. Bandura explained self-efficacy to be one's ability to manage and perform appropriate actions to satisfy desired objectives, and the level, overview and potency across actions and settings [5]. Although previous campaigns have begun with a cognitive behavioural theory purposes (CBT), they have failed to demonstrate a change, and in cases where success is seen, sustainability is lacking [6] [7] [8].

It is important to understand and distinguish an intervention from a Public Health campaign. An intervention is a set of actions with a coherent objective to bring about change or produce identifiable outcomes. These actions may include policy, regulatory initiatives, single strategy projects, or multi-component programmes [9]. Public Health campaigns are different in that they "intended to promote or protect health or prevent ill health in communities or populations". Interventions are intended to prevent or treat illness in individuals [10].

\section{Terminology}

This study defines medicine use as increase in the awareness of the general public on medicine use, through building a culture and operating environment that support medicine use improvement.

Over the past 40 years, the concept of "use of medicines" has been captured by utilising various terms such as Pharmaceutical Care, Medicines Management and the most current one being Medicine Optimization. "Table 1" summarizes their definitions in the context of medication use.

The objective of this review is to evaluate the characteristics of the Public Health campaigns that have addressed medicine use and/or medicine awareness 
Table 1. Common terms for "use of medicine".

\begin{tabular}{|c|c|}
\hline Terms & Definition \\
\hline Pharmaceutical Care & $\begin{array}{l}\text { The responsible provision of drug therapy for the purpose of achieving } \\
\text { definite outcomes that improve a patient's quality of life [11] }\end{array}$ \\
\hline Medicines Management & $\begin{array}{l}\text { Medicines management supports better and more cost-effective } \\
\text { prescribing in primary care, as well as helping patients to manage } \\
\text { medications better. Good medicine management can help to reduce the } \\
\text { likelihood of medication errors [12] }\end{array}$ \\
\hline Medicine Optimisation & $\begin{array}{l}\text { Medicines optimisation represents a step change, it is a patient-focused } \\
\text { approach to getting the best from investment in and use of medicines } \\
\text { that requires a holistic approach, an enhanced level of patient centred } \\
\text { professionalism, and partnership between clinical professionals and a } \\
\text { patient [13] }\end{array}$ \\
\hline
\end{tabular}

during the last 10 years. The key words and combination used for this literature extraction have been mentioned in "Table 2".

\section{Method}

This literature review focuses on investigating the Public Health campaigns that include medicine use and awareness and/or have focused on both concepts at the same time. The objective of this review is to evaluate the characteristics of the Public Health campaigns that have addressed medicine use and/or medicine awareness during the last 10 years.

The Preferred Reporting Items for Systematic Reviews (PRISMA) guidelines were considered appropriate for use in this systematic review as it requires transparent reporting [14] [15].

The PRISMA guidelines were used as a checklist for inclusion of studies [16]. Flow chart in Figure 1 demonstrates this selection process.

\subsection{Literature Search}

The following databases were used: PubMed, Science Direct, and Web of Knowledge, Scopus, Global Health, and Google Scholar. Grey literature is part of the Public Health campaigns that are published as policy and not necessarily in peer-review journals. This literature review also included the grey literature which "is defined as literature that is not produced or distributed by commercial publishers" [17]. It can be in the form of program reports, newsletters, conference proceedings, and abstracts. In this study, the grey literature was obtained from the Google database.

The MeSH headings and Boolean operators used are listed in "Table 2", each keyword was searched individually, and the results of the search were combined in order to make the final selection of papers.

The word "OR" is a representative of the combination of alternative terminologies to find any articles containing one of the key words being searched. Subsequently, the results of the separated number of hits for each word have been combined with "AND" in order to get the most relevant publications. 
Table 2. The key words and combination used for literature extraction.

\begin{tabular}{lll}
\hline Key words & & Key word combination \\
\hline Medication awareness & OR & Medicine awareness \\
Medication Use & OR & Medicine Use \\
Medication campaign & OR & Medicine campaign \\
$\begin{array}{l}\text { Medication use campaign } \\
\text { "Public Health" AND "Medication campaign" }\end{array}$ & OR & Medicine use campaign \\
$\begin{array}{l}\text { "Public Health" AND "Medication awareness } \\
\text { campaign" }\end{array}$ & OR & $\begin{array}{l}\text { "Public Health" AND "Medicine awareness } \\
\text { campaign" }\end{array}$ \\
$\begin{array}{l}\text { "Public Health" AND "Medication use } \\
\text { campaign" }\end{array}$ & OR & $\begin{array}{l}\text { "Public Health" AND "Medicine use } \\
\text { campaign" }\end{array}$ \\
\hline
\end{tabular}

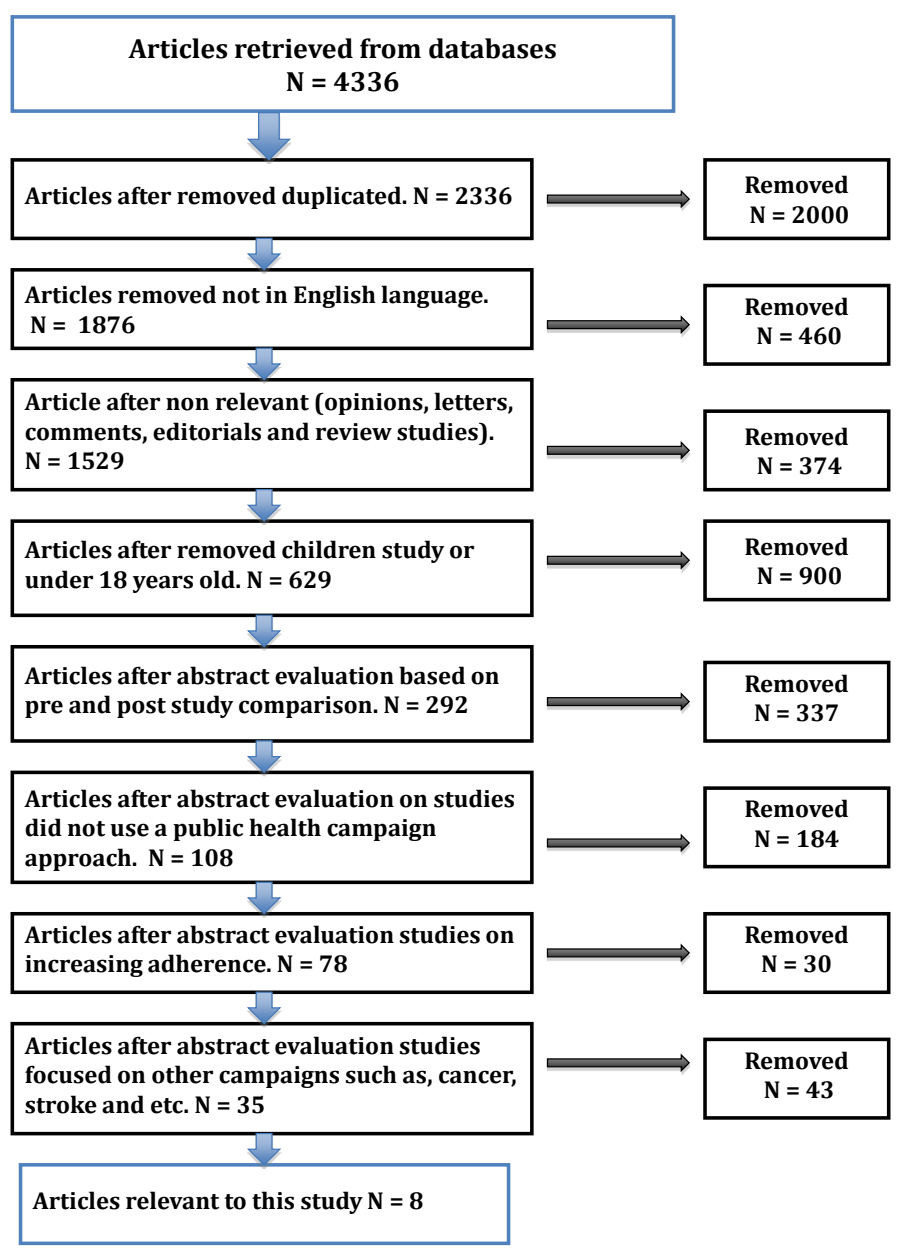

Figure 1. Flow diagram representing the data extraction for this systematic literature review.

\subsection{Inclusion Criteria}

Publications between 01/01/2006 to 01/12/2016 with a target audience of adults over the age of 18 , where both male and female were selected, only the journals published in the English language or translated to English, were considered. This 
time period is selected because, government policies are changing constantly and the most updated data are more likely to represent the new policies while in addition, there has been more use of technology in Public Health campaigns in the last 10 years. Campaigns, which focus on raising awareness, aim to find approaches on explaining certain issues to the public and therefore, disseminate knowledge to individuals in order to allow them to make decisions on their own, instead of being prescriptive towards what they should do. These approaches involves the extensive acknowledgement and comprehension of important societal concerns such as general wellbeing, better quality of life as well as facilitating the achievement of health-related millennium development goals [18]. This is in addition to increasing self-awareness, which allows individuals to understand the concepts and ideas behind a campaign in order to develop a personal understanding on these issues [19]. In case of these studies, the aim is to provide adequate information to the public to alter their behaviour and understanding towards the appropriate use of medicine.

This study only included articles that considered pre and post comparison frameworks were included.

\subsection{Exclusion Criteria}

Two types of studies were excluded from this review. The first type was studies related to drug abuse and misuse, as they are not part of routine medicine therapy. The second type was opinions, letters, comments, and editorials. Studies focusing on children and written in native languages other than English were not included.

\subsection{Articles Selected}

The first author was responsible for identifying, extracting, and reviewing the papers. The quality of the materials and the publication used within this literature review were checked through regular meetings between the research team. Eight articles "Table 3" were considered to have met the inclusion criteria, and the researchers all confirmed the quality and relativeness of these papers. The grey literature search produced four more campaigns, which focused on medicine awareness "Table 4".

\section{Results}

The total number of articles obtained in terms of medicine use and/or awareness and/or Public Health campaign between the periods of 2006 to 2016, was 4336 . This number was then reduced further by removing the 2000 duplicated articles and another 460 articles which were not in the native language of English or had not been translated to English, leaving 1876 articles, decreasing the numbers further by removing 374 based on opinions, letters, comments, editorials, and reviews. Following this, 900 were identified to have included studies on children and young adults under 18 years of age, bringing the total down to 602. The 
Table 3. Summary of studies related to medicine use and awareness in Public Health campaign.

\begin{tabular}{|c|c|c|c|c|c|}
\hline $\begin{array}{l}\text { Reference } \\
\text { (Country) }\end{array}$ & Intervention & duration & Intervention materials & $\begin{array}{c}\text { Sample } \\
\mathrm{N}\end{array}$ & Key finding \\
\hline $\begin{array}{l}\text { 1. Gupta et } \\
\text { al. (2015). } \\
\text { USA }\end{array}$ & $\begin{array}{l}\text { Assess the impact of a } \\
\text { pharmacist-led, web } \\
\text { based video presentation } \\
\text { in increasing patients' } \\
\text { awareness of the } \\
\text { importance of } \\
\text { medication adherence }\end{array}$ & 1 month & $\begin{array}{l}\text { A 15-minute pharmacist-led } \\
\text { based video, pre and post survey. }\end{array}$ & 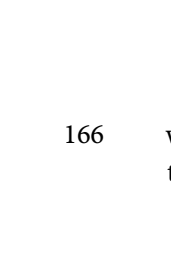 & $\begin{array}{l}\text { The primary find was measurement of change } \\
\text { in patients' awareness of the importance of } \\
\text { medication adherence. The second outcome } \\
\text { was patient's change in knowledge of questions } \\
\text { to ask regarding their medications during their } \\
\text { visits as well as changes in their self-reported } \\
\text { medication adherence. }\end{array}$ \\
\hline $\begin{array}{l}\text { 2. (Burghardt } \\
\text { et al., 2013). } \\
\text { USA }\end{array}$ & $\begin{array}{l}\text { Using educational games } \\
\text { to promote the seeking } \\
\text { of a pharmacist and to } \\
\text { teach key medication use } \\
\text { messages: Results from } \\
\text { an inner city health party }\end{array}$ & 1 week & $\begin{array}{l}4 \text { Game messages, design, } \\
\text { measured game impact via } \\
\text { knowledge and perception } \\
\text { questions with responses } \\
\text { compared between a } \\
\text { non- intervention group and a } \\
\text { control group. }\end{array}$ & $\begin{array}{l}99 \\
\text { participants } \\
\text { in the } \\
\text { intervention } \\
\text { group and } 94 \\
\text { in the control } \\
\text { group }\end{array}$ & $\begin{array}{l}\text { Game participants were significantly more } \\
\text { likely than the control group to indicate they } \\
\text { would seek pharmacist medication advice in } \\
\text { the future. }\end{array}$ \\
\hline $\begin{array}{l}\text { 3. Martin et } \\
\text { al. (2013). } \\
\text { USA }\end{array}$ & $\begin{array}{l}\text { A cluster randomized } \\
\text { controlled trial using a } \\
\text { two arm parallel design. }\end{array}$ & $\begin{array}{l}6 \text { months } \\
\text { follow up }\end{array}$ & $\begin{array}{l}\text { The educational intervention } \\
\text { consists of a seven-page letter size } \\
\text { paper brochure developed } \\
\text { specially for this trial. Active } \\
\text { group received a novel } \\
\text { educational intervention } \\
\text { detailing risks and safe alternative } \\
\text { to their current potentially } \\
\text { inappropriate medication. } \\
\text { Participants followed for } 1 \text { year } \\
\text { while the control group will be } \\
\text { wait-listed for the intervention for } \\
6 \text { months and receive usual care } \\
\text { during that time period. }\end{array}$ & (1) & $\begin{array}{l}\text { Engaging physicians and pharmacists in } \\
\text { collaborative discontinuation of } \\
\text { Benzodiazepine drug is a novel approach to } \\
\text { reduce inappropriate prescriptions. By directly } \\
\text { empowering patients and increasing their } \\
\text { knowledge. }\end{array}$ \\
\hline $\begin{array}{l}\text { 4. Huang et } \\
\text { al. (2006), } \\
\text { and Wen et } \\
\text { al. (2007). } \\
\text { Taiwan }\end{array}$ & $\begin{array}{l}\text { Evaluate the effect of } \\
\text { education program by } \\
\text { analysing the changes in } \\
\text { knowledge of drug } \\
\text { therapy among the } \\
\text { participating public of } \\
\text { pre and post study. }\end{array}$ & 3 months & $\begin{array}{l}\text { Training and pre and post } \\
\text { questionnaire. }\end{array}$ & $\begin{array}{l}\text { 955, but only } \\
514 \\
\text { participants, } \\
\text { completed } \\
\text { both pre and } \\
\text { post } \\
\text { intervention }\end{array}$ & $\begin{array}{l}\text { Medication knowledge of the general public } \\
\text { can be improved through a Nationwide } \\
\text { community university program in which } \\
\text { pharmacist play inactive role in delivering the } \\
\text { knowledge. The program benefits those who } \\
\text { are elderly and less educated. It is also } \\
\text { anticipated that the program will prove to be } \\
\text { an important contributing factor in the } \\
\text { reduction of inappropriate use of medications, } \\
\text { improving the health of the population in } \\
\text { Taiwan. }\end{array}$ \\
\hline $\begin{array}{l}\text { 5. Shen et al. } \\
\text { (2006). USA }\end{array}$ & $\begin{array}{l}\text { Evaluation of a } \\
\text { Medication Education } \\
\text { Program for Elderly } \\
\text { Hospital In-Patients. }\end{array}$ & $\begin{array}{c}3 \text { - } 5 \\
\text { consecutive } \\
\text { days. }\end{array}$ & Training sessions. Focus group & 86 & $\begin{array}{l}\text { Evaluation of this project showed that the sig- } \\
\text { nificantly improved elderly patients' } \\
\text { knowledge about their medication. This, } \\
\text { practical, nursing-staff-conducted program } \\
\text { worked well in a hospital setting and } \\
\text { resulted in improved medication knowledge. }\end{array}$ \\
\hline $\begin{array}{l}\text { 6. Shehadeh } \\
\text { et al. (2015), } \\
\text { Jordan }\end{array}$ & $\begin{array}{l}\text { A structured pre and } \\
\text { post educational } \\
\text { questionnaire, } \\
\text { knowledge about } \\
\text { appropriate antibiotics } \\
\text { use and resistance was } \\
\text { evaluated among a } \\
\text { sample of adults. }\end{array}$ & 3 months $\mathrm{I}$ & Educational card about antibiotics & 271 & $\begin{array}{l}\text { Using tailored education material targeting } \\
\text { antibiotic need and use with a major aim of } \\
\text { improving the public knowledge about } \\
\text { antibiotics can be effective and feasible } \\
\text { strategy. }\end{array}$ \\
\hline
\end{tabular}




\begin{tabular}{|c|c|c|c|c|c|}
\hline $\begin{array}{l}\text { 7. McNulty et } \\
\text { al. (2010), UK }\end{array}$ & $\begin{array}{l}\text { Active and control group } \\
\text { were questioned face to } \\
\text { face about their attitudes } \\
\text { to and use of antibiotic } \\
\text { pre and post antibiotic } \\
\text { campaign. }\end{array}$ & 1 week & Poster and leaflet & $\begin{array}{l}1706 \text { English and } \\
182 \text { Scottish } \\
\text { adults in January } \\
2008 \text { and by } 1707 \\
\text { English and } 123 \\
\text { Scottish adults in } \\
\text { January } 2009 \text {. }\end{array}$ & $\begin{array}{l}\text { There was minimal evidence that public } \\
\text { antibiotic campaign were effective. The } \\
\text { use and visibility of future campaign } \\
\text { materials need auditing. }\end{array}$ \\
\hline $\begin{array}{l}\text { 8. (Giordano et } \\
\text { al., 2013), USA }\end{array}$ & $\begin{array}{l}\text { A Clinic-Wide Social } \\
\text { Marketing Campaign to } \\
\text { Improve Adherence to } \\
\text { antiretroviral Therapy } \\
\text { for HIV }\end{array}$ & 4 weeks & $\begin{array}{l}\text { Video, posters, pens, mugs, label } \\
\text { buttons with the campaign slogan }\end{array}$ & $\begin{array}{l}250 \text { only } 141 \\
\text { people recruited. }\end{array}$ & $\begin{array}{l}\text { Among the } 39.7 \% \text { of participants who } \\
\text { correctly identified the campaign slogan } \\
\text { on the post-intervention survey, } \\
\text { adherence increased by } 3.3 \% \text {, while it } \\
\text { decreased in the other participants by } \\
5.5 \% \text { (paired t -test p = 0.07). The } \\
\text { well-received campaign did not increase } \\
\text { short-term adherence to ART, but } \\
\text { adherence tended to increase in } \\
\text { participants who were more engaged } \\
\text { with the intervention. }\end{array}$ \\
\hline
\end{tabular}

Table 4. International campaigns identified as the grey literature.

\begin{tabular}{|c|c|c|}
\hline $\begin{array}{l}\text { Campaign name } \\
\text { Country }\end{array}$ & Aim and objectives & Message \\
\hline $\begin{array}{l}\text { Get to Know your Medicines } \\
\text { Campaign } \\
\text { (Australia) (NPS, 2007) }\end{array}$ & $\begin{array}{l}\text { Reduce the number of medicine } \\
\text { Related problems in the community by } \\
\text { encouraging older people to be more } \\
\text { informed about their medicines } \\
\text { and giving them the confidence to seek } \\
\text { information from their health professionals. }\end{array}$ & $\begin{array}{l}\text { - Medicines do not just come on prescription. Medicines and } \\
\text { remedies bought at pharmacies, supermarkets and health food } \\
\text { shops are also medicines. Such medicines may react with your } \\
\text { prescription medicines and each other. } \\
\text { - Keep an up-to-date list of your medicines, and go over the list } \\
\text { with your doctor regularly. } \\
\text { - Know where to find reliable information about your medicines. } \\
\text { - Take an active role in your health care. Talk openly with your } \\
\text { - Goctor and pharmacist about your medicines. } \\
\text { original brand of the medicine. Talk to your doctor about the } \\
\text { potential benefits of using generic. }\end{array}$ \\
\hline $\begin{array}{l}\text { Script you Future campaign } \\
\text { (USA) (Script Your Future, } \\
\text { 2015b; Gupta et al., 2015) }\end{array}$ & $\begin{array}{l}\text { Raise awareness among consumers and their } \\
\text { family caregivers about the importance of taking } \\
\text { medication as prescribed as a vital first step } \\
\text { toward better health outcomes. }\end{array}$ & $\begin{array}{l}\text { The campaign focuses on patients affected by three serious chronic } \\
\text { conditions-diabetes, respiratory disease, and cardiovascular } \\
\text { disease. It encourages patients and health care professionals to } \\
\text { better communicate about ways to improve medication adherence. }\end{array}$ \\
\hline $\begin{array}{l}\text { Medicine optimisation } \\
\text { campaign } \\
\text { (UK) (PSNC, 2013). }\end{array}$ & $\begin{array}{l}\text { The campaign highlights the importance of } \\
\text { medicines adherence and the expertise available } \\
\text { within community pharmacy to support patients } \\
\text { in getting the best out of their medicines and } \\
\text { reveals statistics from a new patient survey about } \\
\text { how the public take their medicines. }\end{array}$ & $\begin{array}{l}\text { - Why you should take your medicine as prescribed } \\
\text { - What your medicines does. } \\
\text { - When and how you should take your medicine. }\end{array}$ \\
\hline $\begin{array}{l}\text { Know your medicines } \\
\text { (Malaysia) (Know Your } \\
\text { Medicine, 2013) }\end{array}$ & $\begin{array}{l}\text { Increase consumer awareness of the rational us } \\
\text { of medicines. }\end{array}$ & $\begin{array}{l}\text { Provide consumers with information on different issues related } \\
\text { to health and medicine. } \\
\text { - Ensure that consumers know their medicine, what they should } \\
\text { and should not be taken, and why. } \\
\text { - Increased adverse drug reporting through patient education } \\
\text { Improve knowledge in the use of medicine by pregnant women, } \\
\text { nursing mothers and children. }\end{array}$ \\
\hline
\end{tabular}


abstract of the remaining articles were reviewed and the total number was reduced further by 337, because studies did not have a focus on pre and post campaigns. Another 184 articles were eliminated by as they were declared to be irrelevant, since they did not use a Public Health campaign approach. Following that, the researcher removed another 30 , which were directly measuring the increase in adherence or were measuring adherence, leaving a total of 51. Through the review of abstract another 43 articles were removed because they were based on Public Health campaigns focusing on increasing awareness of a disease such as breast cancer, bowl cancer, stroke, blood pressure etc., and were not targeting medicine and its use, as medicine use was part of their exclusion criteria. The total number of articles remaining, which were considered relevant to the aim of this systematic review, was 8 . Thus, following the identification of the 8 journals, 4 campaigns were identified within the grey literature, which brought the total campaigns investigated in this paper to 12 .

The 12 campaigns which satisfied the inclusion criteria were undertaken in different locations: USA [20] [21] [22] [23], Canada [24], Taiwan [25] [26], Jordan [27], UK [28] [29], Australia [30], Malaysia [31] [32], while one of the campaigns had an international approach [33].

\subsection{Study Characteristics}

The eight studies addressed in this review, all undertook a pre and post- campaign survey, where the follow-up assessment ranged from 4 hours [20] to 12 months [28], however, the majority of the researchers had a follow-up period of 4 months. The sample size varied from 60 [30] to 3718 individuals [28]. One study had a general focus on medication adherence [23], while other studies focused on increasing awareness and knowledge of the public in regards to specific medications; chronic users of benzodiazepines [24], use of antibiotics [27] [28] and antiretroviral therapy (ART) [20].

One study focused on impact of an education program on safe use of medications, studying patients with one regular medication [30]. Three studies [25] [26] [21] focused on general application of knowledge on the awareness of participant's medication as well as the associated risks of the medication and the need to seek information from professionals. While the grey literature similarly, reported the focus on medication adherence [29] [33], and how to promote rational use of medication [31] [32].

\subsection{Goals of the Campaigns}

In four of the studies [20] [23] [29] [33], the focus of the campaign as well as the primary outcome was on medicine adherence which was measured through self-assessment surveys following the campaign. While the remaining campaigns focused on appropriate use of medication through knowledge transfer [21] [24] [25] [26] [27] [28] [30] [31] [32]. 


\subsection{Study Settings}

The principal settings for the interventions differed from one study to another. In three of the studies the interventions were conducted in a community pharmacy, [21] [23] [29], two in a clinic [20] [24], another two in a community university [25] [26] and one was undertaken in a hospital [30]. The remaining studies used a sample of the general public for their campaign. Individuals were approached and asked to take part in the study, [27], or by assistance from a market research company which randomly selected individuals from the general population [28]. The remaining campaigns took place in various geographical places across a country using different platforms and locations, (i.e. pharmacies, hospital, health clinics and street stands [29] [31] [33].

\subsection{Promotional Tools Used by the Campaigns}

Health-care professionals undertook all the campaign. However each campaign made use of various promotional tools to convey their message to the audience.

\subsubsection{Video}

One study used a web-based video presentation [23] led by a pharmacist in raising awareness on the importance of adherence to medication for patients. Information was collected with regards to understating of the participant's existing use of resources for information on medication and willingness to seek help from healthcare professionals about their prescribed medication.

\subsubsection{Brochure}

One study used written educational material, as the main tool for their campaign [24]; a seven-page paper brochure was used. The pre-campaign questionnaires were mailed to the participant and were completed at their homes. The follow-up questionnaire was conducted through a telephone interview.

\subsubsection{Face-to-Face Education}

In in Shen et al.'s (2006) [30] study, medication details were taught to the participants over three days, one hour each day, their knowledge was recorded prior to the course using face-to-face interviews, and after the course following a home visit after being discharged from the hospital, by a registered nurse.

Shehadeh et al.'s (2015) [27] study, involved a pharmacists conducting a 10 minute dialogue session with participants to complete a pre-campaign questionnaire, which was followed by a verbal education using cards that contained key information in regards to appropriate use of antibiotics. Another study conducted a face-to-face questionnaire about attitudes of participants toward use of antibiotics after the campaign. A range of questions in regards to individual's attitude, demographic background as well as socioeconomic conditions were covered. Their exposure to previous campaigns was also explored to make a comparison to individual's exposure and attitude toward appropriate use of antibiotics [28]. 
Giordano et al.'s (2012) [20] study used patient mentors to create a 10-minute video tape to educate the participants on the advantages of adherence to Antiretroviral Therapy (ART) medication. Patient mentors are previous patients who have been trained to support and guide other patients.

\subsubsection{Educational Games}

Burghardt et al.'s (2013) [21] study, used four educational games related to medicines, to create new knowledge in regards to the importance of appropriate and rational use of medication. Game impact was evaluated through a verbally conducted questionnaire.

Two studies focused on running an educational program led by pharmacists, at a university, where 14 classes were offered on the use of medication, patient's rights, medication related regulation and policies. Each participant was asked to complete a questionnaire before the start of the semester comprising of 70 questions and one after each class, comprising of 5 questions [25] [26]. These studies focused on knowledge of individuals on source of drug information, creditability of that information, and individual's perception of pharmacist's roles and purpose.

\subsubsection{Additional Tools}

Some of the campaigns [20] [29] [30] [33], used additional components to convey their message across, which are listed in "Table 5".

Another study focused on creating advertising-style messages to attract and provoke patients with chronic kidney diseases to seek more information about their recommend medications. Preliminary surveys were conducted to determine the impact of such messages and improve them to identify the more effective ones. Participants were given time to conduct self-reflective tasks using paper printouts, to allow them to prepare and share their perception in a group discussion [22].

\subsection{Measurements of Impact}

The impact of the campaigns in this review was measured through a direct comparison among the pre and post-campaign surveys or questionnaires.

The primary outcomes of four studies [21] [23] [27] [30] demonstrated a

Table 5. Additional promotional tools used by campaigns.

\begin{tabular}{lc}
\hline Tools utilised & Reference \\
\hline Interactive websites & {$[29][31][33]$} \\
Public announcements by televisions and radios & {$[33]$} \\
Door hangers, wallet cards), leaflets & {$[29][31][33]$} \\
Label buttons for staff and physician to wear & {$[20]$} \\
Posters & {$[20][29][31][33]$} \\
Free mugs, and pens & {$[20]$} \\
\hline
\end{tabular}


statistically significant increase, in awareness of the public in regards to medication adherence [23], medication knowledge of the patients [30], improved knowledge of antibiotics in regards to missing doses, not completing a treatment, using leftover medications and excessive use of antibiotics, which can lead to increased resistance [27]. Individuals taking apart in educational games [21] and educational intervention [25] [26] were substantially more likely to seek advice from pharmacists [21] and significant increase in medication knowledge was observed [25] [26].

Martin et al.'s (2012) [24] study was designed to assess the rate at which the use of benzodiazepines was being discontinued in an attempt to reduce inappropriate prescriptions. The study aimed to measure such knowledge empowerment through determining the long-term sustainability of these changes. This study is only a proposed plan for a campaign and is yet to be implemented.

The remaining studies were not successful in portraying a significant impact [20] [28]. Face-to-face questionnaires failed to demonstrate an increased in adherence of ART medication [20]. Similarly, no significant improvement was seen in understanding the ineffectiveness of the use of antibiotics for colds and coughs, while overall no improvement was observed in the appropriate use of antibiotics. However, a $20 \%$ increase in the enquiry of information on antibiotics was seen between the public and their general practitioner (GP) [28].

\section{Discussion}

This review aimed to critically analyze all Public Health campaigns that have addressed medicine use and awareness during the last 10 years, and to identify factors that have led to their success or failure. A total of 12 campaigns from peer-review literature and grey literature were analyzed and four demonstrated a significant improvement in medication adherence and/or medicine knowledge.

Educational tools and self-efficacy were used in previous studies to develop successful campaigns. Self-efficacy can be defined as a performance-based evaluation of observed capability [5].

Gupta et al. (2015) was successful in increasing patient awareness of medication adherence and encouraging patients to utilize pharmacists and physicians [23]. A positive impact from their web-based campaign was seen on patient adherence, due to the emphasis placed on patient-centered outcomes. An educational campaign with a continuous contact with patients and behaviour support has led to significant increase in primary outcomes. This reflects the increase in awareness of participants on the importance of medication adherence [23]. A total of 166 people participated, out of which a higher number of patients (92 people) in the follow up survey recognised the importance of taking their medication around similar time $(\mathrm{p}=0.002)$, and the impact this could have on their life quality. Patient belief and concerns about medication, impacts to be a great factor on their behaviour toward medication taking and adherence [23]. The success of Gupta et al.'s (2015) [23] campaign was dependent on the participants 
paying full attention to the presentation made by the team. The presentation focused on providing and increasing the knowledge and information, of participants in order for them to understand and learn the numerous educational elements. Thus, attention filters were embedded within the follow-up survey. These filters were a series of question on the information provided in the presentations and were used to eliminate participants, which demonstrated a lack of focus from their answers of the survey [23]. Attention filters consisted of simple and straightforward questions on the contents covered at each stage to ensure participants were paying attention to the material covered. This largely reduced the sample size and thus decreasing the overall reliability of the results. Using an online presentation could result in a reduced focus and attention to the materials due to lack of personalisation and interaction with the audience. The absence of a control group was another drawback of this study, which prohibited the assessment of the effect of external factors that could have influenced the change in medication adherence awareness of individuals within this study. Also, using non-random sampling could have created a selection bias, as volunteers are usually more health-conscious and healthier [23].

Studies conducted by Martin et al. (2013) [24], Shehadeh, Suaifan and Hammad, (2015) [25], McNulty et al. (2010) [28] and Giordano et al. (2013) [20], all focused on increasing awareness of the appropriate and safe use of specific medications. This can be done through educational programs, demonstrated by Martin et al. (2013) [24] who devised a study, which focused on empowering individuals with knowledge about risks [24]. His objective was set around the understanding that using medication effectively can slow the progression of disease, however to this day; medications are not taken by individuals as prescribed [22]. The measurement of self-efficacy was one of the objectives of Martin et al.'s (2013), study although it is useful but it is hard to assess if individual's perception of the term is consistent across a community. Self-efficacy is a concept used to understand health behaviours. This is described as "the sense of having control over one's life" ([20], p. 231). Individuals who are certain that they can control their lives represent high-efficacy characteristics while individuals who believe their lives are controlled by external factors and subject to chance represent low-efficacy characteristics [34]. The focus of the study was on elderly participants of the age of 65 years and older only, which limits the perspective. No limitation on cluster size was set in order to uphold the recruitment needs [24]. The focus of Martin et al.'s (2013) study was to evaluate the impact of a knowledge transfer methodology on chronic users of benzodiazepines at a community based level. This was done through assessing the rate at which the use of benzodiazepine was being discontinued by taking measurements at intervals of 6 months and 1 year, in an attempt to determine the long-term sustainability of these changes. The secondary objectives of this research was focused on the change of risk evaluation and self-efficacy of users on terminating benzodiazepines, in order to encourage individuals to discuss with safer prescribing ap- 
proaches with their physician or pharmacist. This is design study which is yet to be implemented in real life.

The study conducted by Shen et al. (2006) [30] demonstrated that following an educational course, which was conducted for half an hour on 3 - 5 consecutive days to 60 patients, over the age of 65 years, resulted in improvements of medicines awareness. The medication knowledge of individuals in terms of brand names, times and dosage, and medication purpose increased by $40 \%, 30 \%$ and $10 \%$ respectively. Knowledge was documented after their release from the hospital following a home visits and then compared to their recorded knowledge prior to the educational program. Thus, suggesting educational methods conducted by nurses and staff to be effective in hospital setting. The number of participants within this study was relatively small, and the outcomes were measured at the control of the participants as they were asked to participate in the post-campaign survey at the comfort for their homes, which can introduce bias. Only English speaking participants were considered in this study, which greatly limited the scope of the study [30].

Resistance to antibiotics is a global issue, which poses threats to Public Health and costs, as it can result in treatment failure [35]. Previous studies [36] [37], support Shehadeh, Suaifan, and Hammad, (2015), in demonstrating the importance of an increase in public knowledge using educational interventions [27]. An educational campaign was designed by Shehadeh, Suaifan, and Hammad, (2015), which ran over a course of 3 months. The results, demonstrated a higher degree of awareness for the excessive use of antibiotics by pregnant women, young children and lactating mothers, and most of participants came to the realisation that correct use of antibiotic is important and it should only be prescribed by physicians rather through self-prescription [27]. After the completion of the campaign, an improvement was observed in the knowledge level of the participants regarding safe and appreciate use of antibiotics regarding as well as resistance developed to antibiotics where the post-campaign demonstrated an increase of $30 \%, 52 \%$ and $17 \%$ respectively. This study was a pilot study with only 14 participants ( $5 \%$ of the target sample), which means these results are not generalisable to the population. The data was not gathered in a demographic manner, which means the sample cannot be fully described and therefore the effectiveness of the campaign cannot be understood in respect to various subtype of individuals [27].

Similar educational tools were used by the Centre for Disease Control and Prevention referred to as "Get Smart: Know When Antibiotics Work". These have proven that educational approaches and interventions relying on assistance of pharmacists can be effective in promotion of adherence to suitable prescription instructions [38].

Patient-based interventions have shown to be the most effective approach to reducing antibiotic use [39]. This approach is centred on the patient and required the provision of advice to individuals in regards to history of the disease, ineffectiveness of certain medications such as antibiotics and the consequent 
side effects and how they can control their symptoms using appropriate medications. Similarly McNulty et al. (2010) developed a national campaign in the UK to promote patients to take fewer antibiotics [28]. However, this study showed no improvement from a previously conducted national campaign in 2008 within the UK, either in Scotland or England. The lack of understanding when it comes to the benefits of antibiotics on colds and coughs, no improvements were seen in the use of antibiotics. Giordano et al., (2013) focused on adherence to antiretroviral therapy (ART) for HIV patients where 141 people were recruited to take part over a course of 4 weeks [39]. Among the $39.7 \%$ of participants who correctly identified the campaign slogan on the post-campaign survey, adherence increased by $3.3 \%$, while it decreased in the other participants by $5.5 \%(\mathrm{p}=$ 0.07). Adherence was measured through a self-reported, pre and post intervention survey. The well-received campaign did not increase short-term adherence to ART, but adherence tended to increase in participants who were more engaged with the campaign. According to Giordano et al. (2013) [20] the underlying reason behind the failure of their study to improve adherence to ART, was due to the ambiguity of the message for participants through insufficient internalisation of the campaign. As the results demonstrated that only $40 \%$ of the total 141 participants managed to understand and identify the message of the campaign properly [20]. However, social marketing has previously obtained success in Public Health when appeals were made to encourage condom use and therefore reduce high-risk behaviours [20]. Social marketing aims to create and combine various marketing principles with other methods in the hope of influencing individual behaviours in a way that will benefit them and their communities for superior social status [40]. Giordano et al. (2013) [20] and Gibson et al. (2010) [41] achieved success in their social marketing campaign, which addressed intravenous (IV) drug user to use lower risk injections [20] [39]. This study approached 302 individuals from a target population of 250 participants, only 141 participants took part in the post-campaign survey. In this investigation, an improvement in adherence was not seen in the campaign. This was because only $40 \%$ of the applicants could understand the message of the campaign correctly. Moreover, patients were not pursued for follow-up questionnaires due to lack of resources, and not all 109 of the original participants completed the post-campaign survey. The self-reported adherence at the baseline could have also introduced bias [19] as their responses may be inclined towards an ideal answer they believe will represent them well within a community, instead of the reality which may portray them differently. The adherence was reported to have decreased from pre to post campaign but there was no control group [20].

As mentioned earlier, three studies [21] [25] [26] focused on the use of knowledge transfer method to improve medication awareness within the community. This means patients were provided with appropriate information through various methods such as an educational game, and pharmacist-facilitated education program to inform them of the available resources on medications and the im- 
portance of medication use and side effects in case of inappropriate use. An educational game involves dispersion of information through a game, while a pharmacist- facilitated education program involves the participants being education by pharmacist through information provided by the healthcare professional on importance of appropriate medicine use. A study conducted by Burghardt et al. (2013), focused on increasing health literacy elements in order to motivate the empowerment of individuals to pursue information [21]. This resulted in an overall increase of patient knowledge and consequently encouraged patients to obtain information and state their preferences in regards to their healthcare [21].

Huang et al. (2006) [25], investigated the use of social cognitive theory by considering the sequential cause relationships between, knowledge, attitude and practice (KAP), and confirmed individuals who are deprived of healthcare knowledge are those who do not seek appropriate medical service and are therefore inclined to illnesses [25] [42]. Current promotional elements of Public Health efforts utilise a community-based methodology to increase awareness of the community concerning the issues at hand. Huang et al. (2006) aims to motivate interest in adaptation of behaviours, which will improve health and quality of life while decreasing health risks and accidental injuries, which occur due to lack of sufficient knowledge [25]. Huang et al. (2006) [25] recruited pharmacists, to educate individuals over 4 months, where 955 individuals participating in 31 community universities. A single group pre and post-comparison study was conducted, which demonstrated improved knowledge [25]. In the past systematic and stepwise education, programs have demonstrated a greater impact compared to other approaches, in disseminating knowledge and that the content and method of the education program is more effective on increasing knowledge than the time spent on it.

Similarly, Wen et al. (2007) [26], managed to successfully utilise a national medication education program to promote healthcare professionals as a public source of information. The results indicated that participants were more likely to seek drug information from healthcare professional in comparison to the baseline $(\mathrm{p}<0.05)$. Participants also had more confidence in the provided information from community pharmacists. Previous research indicates that pharmacists have been effective mediators in increasing patient medication adherence through their expert training and knowledge in medication [23] [43] [44].

Another study demonstrated the effectiveness of exploiting a health party setting. This comprised of educational games being played, screening booths were provided along with presence of music, and gifts to promote participation of individuals. This aim was to create a more relaxed approach where cultural and health literacy barriers can be removed to encourage communication in smaller communities that face cultural and racial barriers [21].

\subsection{Grey Literature Campaigns}

The "Script Your Future Campaign", was successful in raising consumer aware- 
ness through addressing the problem and promotion of medication adherence, for chronic diseases [23]. This was achieved through increased communication between patients and healthcare professionals [33]. The campaign conducted a survey nationally, before the launch of the campaign to determine the target market baseline in 2011 to assess the awareness of adherence to medication as part of a health problem, while also exploring communication among healthcare providers and patients [45]. Surveys were conducted midpoint in 2013 and again in 2015 to compare the results and the level of outreach. The impact of the campaign was assessed by looking into the knowledge of individuals in regards to medication adherence and identifying the number of individuals who recognised this to be a health issue [46]. However, this campaign is still running, and no results have yet been published in order to assess its effectiveness.

For "Get to Know Your Medicines" campaign no evaluation has been conducted yet [30]. The Medicines Optimisation Campaign surveyed, 1500 members of the public in UK between Jun to July 2013. The results revealed that $74 \%$ of the participants acknowledged that they are more likely to adhere to their medicines as prescribed, if they had known more about the medications and their associated side effects, and many had been unaware of the information, advice, and support available to them through pharmacists [29]. This suggests that methods aiming at increasing awareness through providing knowledge and appropriate information such as side effects of medicines do have the potential to be effective in altering the medicine intake behaviour of individuals. The result of the Medicines Optimisation Campaign survey support previous results that patients struggle in following specific treatments. The reasons behind this can be complex, many do not understand the role of the medication, many do not know the support available to them, and many do not understand the side effects of improper medication use. However this demonstrates that information needs to be customised and tailored to address the individual needs of patients, aiming to tackle individual understanding and practical barriers. When it comes to interpreting and applying this information, the pharmacist is effective on this matter [47].

The "Know Your Medicine" program obtained relatively good results, however the level of participation was low. For those who had taken part, significant improvement was observed in their interpretation and understanding of medicine, in particular on the use of medicine, labelling and registration, type, disposal and source of controlled medicines. However, the evaluation of this study was based on a self-reported assessment, and the actual behaviour of consumers was not recorded [32]. An estimation of the public expenditure on medication, was used based on consumer refill of medication [47]. This was a drawback of this study as bias can be introduced through customer recall, and expenditure on medication does not necessarily mean the medication was used appropriately or at all. Data on public medication expenditure might not be accurate, as many participants may not record all their medication purchases accurately. 


\subsection{Public Health Campaign versus Medicine Intervention}

From the assessment of studies considered in this review the main difference between Public Health and medicine intervention can be identified.

Public Health has a primary focus on the population, based on concerns of individuals and aims to provide services to prevent diseases and emphasis on health promotion for the use of the entire community. The Public Health approach usually focuses on campaigns that are aimed on lifestyle adjustment and behavioural change. Most often health care professional are the ones conducting the campaigns. The major emphasis on Public Health paradigm is threat to health of a community or population. The benefit of this approach is the large number of people targeted through campaigns. Thus, if the right target audiences are approached, using suitable tools, the outcomes should be sustainable and long lasting. However, this is where the challenge lies, identification of a target audience and ensuring delivery is successful to this population could be difficult due to the fact that the method does not necessarily involve individual approaches. It is also hard to ensure all the individuals that participated in the pre-campaign can be approached for the post-campaign evaluations, and decrease in numbers reduces the reliability of any results. Public Health campaigns also require more funding and human resource for implementation of the campaign. Results and behavioural changes would be seen over a longer period of time, and usually the campaign itself is run for a longer time period.

On the other hand, medicine interventions have an emphasis on individuals, and providing personal services in regards to social responsibilities. The main focus is on individual diagnosis, treatment and health care of individual patients, instead of a population unlike Public Health campaign. The medical interventional approach focuses on medical care. Similarly to Public Health, healthcare professional conduct these researches. Within medical education, social science seems to play a key role. The individuality approach of this method means, human resources and funding needed are lower than that of Public Health. It can be argued that knowledge transfer or information provided on a one-to-one basis is more effective, thus, better outcomes are expected. It is easier to approach individuals for both pre and post campaign assessment, thus results could be more reliable.

\subsection{Effect of Public Health Campaigns}

As demonstrated through this systematic review, Public Health campaigns are effective when certain key issues are resolved. This mainly involves the clarity of the message of the campaign. Regardless of the tools used in the campaign, video, written information, face-to-face approaches or educational games, if the message is not clear, the participants will not be able to adapt the necessarily behavioural changes.

It is important to use theoretical models when it comes to developing campaigns, and to ensure success of the campaigns it can to be undertaken at several 
levels, targeting various ages, gender and cultures. It should be easy to understand, and tailored to the specificity of the target audience. It is also important for the campaigns to provide alternatives or solutions to the issues they are aiming to tackle. In this case for example, appropriate use of medications should be demonstrated and an explaination of the risks individual are exposed to if doses are missed or alternated.

Another issue is the time the campaign is run, it is important to dedicate sufficient time to the campaign and information transfer to participants, before behavioural change are expected from a community or population. Another issue is raised when it comes to measuring the outcomes of a campaign, it may be hard to locate the participants, especially if the campaign is ran for a longer period of time. It is also important to dedicate manpower to undertake both pre and post campaign assessments to avoid any bias when it comes answering the questions truthfully.

\section{Conclusions}

It can be concluded that the use of campaigns can lead to improvements in knowledge of individuals and this may lead to initiating behavioral change, through the use of knowledge transfer methodologies as reported by the studies reviewed. However, it is important to ensure the message of the campaign is clear, and is interpreted correctly to the appropriate target audience using various platforms to increase the outreach of the message. This systematic review has suggested an improvement in understanding of individuals in regards to appropriate use of medication with regards to timing and regular use of medication. However, more rigorous and through evaluation of campaigns is needed to determine the overall effectiveness of such approaches in promoting medicine use through behavioural modifications among the public, using a longer campaign period to reach larger percentage of the population, and using a more rigorous form of post-campaign analyses to ensure the individuals who took part in the pre-campaign can be traced to complete the post-campaign survey.

This review has a number of limitations. One of the limitations was the lack of demographic consistency among the studies. The efficacy of the campaigns cannot be determined across various subtypes. Not all the studies have a focus on medicine awareness or adherence. Each study varied in terms of their methodology, measurements, duration, and tools used to conduct the campaign. The studies were collected over a 10-year period. In this period, the definition and understanding of appropriate medication use could have been modified. Studies in other languages were excluded.

This review sheds light onto the lack of available studies, which investigate the impact of campaigns on medicine awareness and aim to increase knowledge on appropriate use of medicine as a whole. The gap identified in this review demonstrates a need for such a study. Future studies should focus on designing a campaign, which aims to increase the knowledge and awareness of individuals 
on the importance of medicine use in a safe and appropriate manner to initiate behavioural changes. If such a campaign is implemented locally but at a national scale, i.e. in local hospital all across a nation, the change can begin to shift the behaviour of the entire population towards appropriate use of medication.

\section{Acknowledgements}

I would like to thank the academic and members of staff in the University of Hertfordshire, UK for their help and support.

Funding: None.

Competing Interests: None Declared.

Ethical Approval: Not required (No animal and human subjects were involved).

\section{References}

[1] Trueman, P., Lowson, K., Blighe, A., Mészáros, A., Wright, D. and Glanville, J. (2010) Evaluation of the Scale, Causes and Costs of Waste Medicines. Report of DH Funded National Project. York Health Economics Consortium and The School of Pharmacy, University of London, York and London.

[2] Brown, M. and Bussell, J. (2011) Medication Adherence: WHO Cares? Mayo Clinic Proceedings, 86, 304-314. https://doi.org/10.4065/mcp.2010.0575

[3] Rogers, E., Storey, J., Berger, C. and Chaffee, S. (1987) Communication Campaigns. In: Handbook of Communication Science, 1st Edition, Sage, Newbury Park, CA, 817-846.

[4] Weiss, J. and Tschirhart, M. (1994) Public Information Campaigns as Policy Instruments. Journal of Policy Analysis and Management, 13, 82-119. https://doi.org/10.2307/3325092

[5] Zimmerman, B. (2000) Self-Efficacy: An Essential Motive to Learn. Contemporary Educational Psychology, 25, 82-91. https://doi.org/10.1006/ceps.1999.1016

[6] Wagner, G., Kanouse, D., Golinelli, D., Miller, L., Daar, E. and Witt, M. (2006) Cognitive-Behavioral Intervention to Enhance Adherence to Antiretroviral Therapy: A Randomized Controlled Trial (CCTG 578). AIDS, 20, 1295-1302. https://doi.org/10.1097/01.aids.0000232238.28415.d2

[7] Parsons, J., Golub, S., Rosof, E. and Holder, C. (2007) Motivational Interviewing and Cognitive-Behavioral Intervention to Improve HIV Medication Adherence Among Hazardous Drinkers. JAIDS Journal of Acquired Immune Deficiency Syndromes, 46, 443-450. https://doi.org/10.1097/QAI.0b013e318158a461

[8] NHS (2016) Cognitive Behavioural Therapy (CBT). Nhs.uk. http://www.nhs.uk/Conditions/Cognitive-behavioural-therapy/Pages/Introduction. aspx

[9] Rychetnik, L., Frommer, M., Hawe, P. and Shiell, A. (2002) Criteria for Evaluating Evidence on Public Health Interventions. Journal of Epidemiology \& Community Health, 56, 119-127. https://doi.org/10.1136/jech.56.2.119

[10] Springston, J.K. (2005) Public Health Campaign. In: Heath, R.L., Ed., Encyclopedia of Public Relations, Vol. 2, SAGE Publications, Inc., Thousand Oaks, 670-673. https://doi.org/10.4135/9781412952545.n341

[11] Hepler, C.D. and Strand, L.M. (1990) Opportunities and Responsibilities in Phar- 
maceutical Care. American Journal of Hospital Pharmacy, 47, 533-543.

[12] Naylor, C., Imison, C., Addicott, R., Buck, D., Goodwin, N., Harrison, T., Ross, S., Sonola, L., Tian, Y. and Curry, N. (2015) Transforming Our Health Care System. The Kings Fund.

http://www.kingsfund.org.uk/sites/files/kf/field/field_publication_file/10PrioritiesFi nal2.pdf

[13] Picton, C. and Wright, H. (2013) Medicines Optimisation: Helping Patients to Make the Most of Medicines. Royal Pharmaceutical Society.

https://www.rpharms.com/Portals/0/RPS\%20document\%20library/Open\%20access/ Policy/helping-patients-make-the-most-of-their-medicines.pdf

[14] Liberati, A., Altman, D.G., Tetzlaff, J., Mulrow, C., Gøtzsche, P.C., Ioannidis, J.P., Clarke, M., Devereaux, P.J., Kleijnen, J. and Moher, D. (2009) The PRISMA Statement for Reporting Systematic Reviews and Meta-Analyses of Studies That Evaluate Health Care Interventions: Explanation and Elaboration. PLoS Medicine, 6, e1000100.

[15] Hemingway, P. and Brereton, N. (2009) What Is a Systematic Review? Hayward Medical Communications, 2, 1-8.

[16] Prisma (2015) Prisma Checklist. Prisma-statement.org. http://www.prisma-statement.org/documents/PRISMA\%202009\%20checklist.pdf

[17] Battle, C.U. (2009) Essentials of Public Health Biology: A Guide for the Study of Pathophysiology. Jones \& Bartlett Publishers, Burlington, MA.

[18] Kumar, S. and Preetha, G.S. (2012) Health Promotion: An Effective Tool for Global Health. Indian Journal of Community Medicine, 37, 5.

[19] Lambrick, M. and Rainero, L. (2010) SAFE CITIES. endvawnow.org. http://www.endvawnow.org/uploads/modules/pdf/1304107021.pdf

[20] Giordano, T., Rodriguez, S., Zhang, H., Kallen, M., Jibaja-Weiss, M. and Buscher, A. (2012) Effect of a Clinic-Wide Social Marketing Campaign to Improve Adherence to Antiretroviral Therapy for HIV Infection. AIDS and Behaviour, 17, 104-112. https://doi.org/10.1007/s10461-012-0295-x

[21] Burghardt, K., Bowman, M., Hibino, M., Opong-Owusu, B., Pokora, T. and Reeves, K. (2013) Using Educational Games to Promote the Seeking of a Pharmacist and to Teach Key Medication Use Messages: Results from an Inner City Health Party. Research in Social and Administrative Pharmacy, 9, 542-552. https://doi.org/10.1016/j.sapharm.2013.01.001

[22] Yank, V., Tribett, E., Green, L. and Pettis, J. (2015) Learning from Marketing: Rapid Development of Medication Messages That Engage Patients. Patient Education and Counseling, 98, 1025-1034.

[23] Gupta, V., Hincapie, A., Frausto, S. and Bhutada, N. (2015) Impact of a Web-Based Intervention on the Awareness of Medication Adherence. Research in Social and Administrative Pharmacy, 12, 926-936.

[24] Martin, P., Tamblyn, R., Ahmed, S. and Tannenbaum, C. (2013) An Educational Intervention to Reduce the Use of Potentially Inappropriate Medications among Older Adults (EMPOWER Study): Protocol for a Cluster Randomized Trial. Trials, 14, 80. https://doi.org/10.1186/1745-6215-14-80

[25] Huang, Y., Wang, H., Yang, Y.K., Lin, S., Lin, H. and Chen, C. (2006) Effects of a National Health Education Program on the Medication Knowledge of the Public in Taiwan. Annals of Pharmacotherapy, 40, 102-108.

https://doi.org/10.1345/aph.1G312 
[26] Wen, M., Lin, S., Yang, Y., Huang, Y., Wang, H. and Chen, C. (2007) Effects of a National Medication Education Program in Taiwan to Change the Public's Perceptions of the Roles and Functions of Pharmacists. Patient Education and Counselling, 65, 303-310. https://doi.org/10.1016/j.pec.2006.08.011

[27] Shehadeh, M., Suaifan, G. and Hammad, E. (2015) Active Educational Intervention as a Tool to Improve Safe and Appropriate Use of Antibiotics. Saudi Pharmaceutical Journal, 24, 611-615.

[28] McNulty, C., Nichols, T., Boyle, P., Woodhead, M. and Davey, P. (2010) The English Antibiotic Awareness Campaigns: Did They Change the Public's Knowledge of and Attitudes to Antibiotic Use? Journal of Antimicrobial Chemotherapy, 65, 1526-1533. https://doi.org/10.1093/jac/dkq126

[29] PSNC (2013) Medicines Optimisation Campaign. PSNC. http://psnc.org.uk/our-news/medicines-optimisation-campaign-2013/

[30] Shen, Q., Karr, M., Ko, A., Chan, D., Khan, R. and Duvall, D. (2006) Evaluation of a Medication Education Program for Elderly Hospital In-Patients. Geriatric Nursing, 27, 184-192. https://doi.org/10.1016/j.gerinurse.2006.03.015

[31] NPS (2007) Get to Know Your Medicines Campaign. NPS Medicine Wise. http://www.nps.org.au/publications/consumer/medicines-talk/pre-2008/mt23/get-t o-know-your-medicines-campaign

[32] Know Your Medicine (2013) Know Your Medicine Programme. http://www.knowyourmedicine.gov.my/en

[33] Script Your Future (2015) Home-Script Your Future. Scriptyourfuture.org. http://www.scriptyourfuture.org

[34] Schneider, M. (2011) Introduction to Public Health. 3rd Edition, Jones and Bartlett Publishers, Boston.

[35] Ozgenç, O., Genç, V., Ari, A., Sibel, E., Saçar, S. and Ozunlu, H. (2011) Evaluation of the Therapeutic Use of Antibiotics in Aegean Region Hospitals of Turkey: A Multicentric Study. Indian Journal of Medical Microbiology, 29, 124-129. https://doi.org/10.4103/0255-0857.81788

[36] Finch, R., Metlay, J., Davey, P. and Baker, L. (2004) Educational Interventions to Improve Antibiotic Use in the Community: Report from the International Forum on Antibiotic Resistance (IFAR) Colloquium, 2002. The Lancet Infectious Diseases, 4, 44-53. https://doi.org/10.1016/S1473-3099(03)00860-0

[37] Misurski, D., Lipson, D. and Changolkar, A. (2011) Inappropriate Antibiotic Prescribing in Managed Care Subjects with Influenza. American Journal of Managed Care, 17, 601-608.

[38] CDC (2016) Get Smart about Antibiotics. Print Materials.CDC. sdc.gov. http://www.cdc.gov/getsmart/community/materials-references/print-materials/inde x.html

[39] French, J. (2013) Consensus Definition of Social Marketing. i-socialmarketingorg. http://www.i-socialmarketing.org/assets/social_marketing_definition.pdf

[40] Gibson, D., Zhang, G., Cassady, D., Pappas, L., Mitchell, J. and Kegeles, S. (2010) Effectiveness of HIV Prevention Social Marketing with Injecting Drug Users. American Journal of Public Health, 100, 1828-1830. https://doi.org/10.2105/AJPH.2009.181982

[41] Baker, D., Parker, R., Williams, M. and Clark, W. (1998) Health Literacy and the Risk of Hospital Admission. Journal of General Internal Medicine, 13, 791-798. https://doi.org/10.1046/j.1525-1497.1998.00242.x 
[42] Sadik, A., Yousif, M. and McElnay, J. (2005) Pharmaceutical Care of Patients with Heart Failure. British Journal of Clinical Pharmacology, 60, 183-193. https://doi.org/10.1111/j.1365-2125.2005.02387.x

[43] Lee, J., Grace, K. and Taylor, A. (2006) Effect of a Pharmacy Care Program on Medication Adherence and Persistence, Blood Pressure, and Low-Density Lipoprotein Cholesterol. Journal of the American Medical Association, 296, 2563-257. https://doi.org/10.1001/jama.296.21.joc60162

[44] Script Your Future (2016) About the Campaign-Script Your Future. Scriptyourfutureorg. http://www.scriptyourfuture.org/about/challenge/

[45] Script Your Future (2016) Script Your Future. Scriptyourfutureorg. http://www.scriptyourfuture.org/faqs-2/

[46] PSNC. http://psnc.org.uk/ http://psnc.org.uk/wp-content/uploads/2013/11/Pfizer-extends-its-medicines-optim isation-public-awareness-campaign-for-2013.pdf

[47] Azmi, M., Akmal, A. and Chua, G. (2014) A National Survey on the Use of Medicines (NSUM) by Malaysian Consumers. Pharmaceutical Services Division and the Clinical Research Centre, Ministry of Health Malaysia.

https://www.pharmacy.gov.my/v2/sites/default/files/document-upload/book.nation al-survey-use-medicines-2.12.pdf 